\title{
Study of wear performance of wheel and rail steels under dry sliding conditions
}

\author{
TP Leso, ${ }^{1,3}$ CW Siyasiya, ${ }^{1}$ RJ Mostert, ${ }^{1}$ J Moema ${ }^{1,2}$
}

\author{
'The Department of Materials Science and Metallurgical Engineering, University of Pretoria, Lynnwood Road, Hatfield, South Africa \\ ${ }^{2}$ Advanced Materials Division, Mintek, 200 Malibongwe Drive, Randburg, South Africa \\ ${ }^{3}$ The Department of Chemical, Materials and Metallurgical Engineering, Botswana International University of Science and Technology, \\ Palapye, Botswana \\ Email: tshenolophinah@gmail.com
}

\begin{abstract}
The demand for efficient railway services has significantly increased in the past years due to an increased demand for the high-speed transportation of goods with high loads. The increase in loads and velocities has resulted in increased problems associated with rolling contact fatigue (RCF), rolling and sliding wear on the wheel and rail materials causing a reduction of service life of wheel/rail systems. Rail operating companies spend significant funds in maintenance and replacing damaged rails and wheels caused by wear. In addition, unscheduled maintenance due to wear and RCF often lead to poor availability of railway networks. For this study, dry sliding wear was investigated on wheel and rail steels using RTEC Multi-Function Tribometer. The results demonstrated that the rig was successful in simulating sliding wear, and that the fractions of the wear components could be varied, and it also provided instrumentation. Information on coefficient of friction against sliding distance and applied force were obtained which were used to compare sliding wear performance of both wheel and rail steels. The wheel was found to perform better than the rail under the same conditions due to its high initial hardness values and smaller interlamellar spacing.
\end{abstract}

\section{Introduction}

\subsection{Wear and Rolling Contact Fatigue (RCF)}

The demand for high-speed transportation of goods with high loads has significantly increased in the past decade resulting in an increase in axle loads and high speeds trains causing problems associated with wear and RCF. Wear can be defined as a process that involves the removal or displacement of material from surfaces that are in contact under an applied load due to plastic deformation with some phase transformation occurring in some cases. ${ }^{1,2}$ Wear occurs due to one or a combination of factors such as adhesion, abrasion and corrosion in the presence or absence of lubricants. ${ }^{2}$ Wear results in deterioration of surface integrity or quality of those contacting materials. During sliding and rolling of a wheel on a rail, the interface of the wheel/rail can experience mechanical wear, chemical wear, thermal wear or a combination of both depending on the working environment. Also, during rolling and sliding of the wheel on rail both the wheel and rail in contact experience rolling contact fatigue (RCF). RCF is a situation whereby the durability of surfaces in contact is significantly reduced due to repeated application of pressure and creep forces in the rail/wheel contact area. ${ }^{3}$ RCF is influenced by several factors which include material properties, the wheel/rail contact geometries, loading conditions, lubrication, inclusions, surface topography which affects generation of local stress distribution at the contact. ${ }^{4}$ Inclusions such as hard and soft inclusion in steel as well as entrapped hydrogen are responsible for crack initiation and propagation which are key dynamics affecting RCF. ${ }^{5,6}$ For example, soft manganese sulphide inclusions act as crack initiators (stress raisers) under cyclic loading which reduces fatigue resistance of rail/wheel materials which may cause fatigue failure. ${ }^{5,6} \mathrm{RCF}$ defects include spalling, shelling, head checks and corrugation. Head cracks have been found to cause some noise in trains and may also cause some rail breakage resulting in accidents. ${ }^{7,8}$ RCF has a competitive relationship with wear at the wheel/rail contact. If the wear rate is greater than the RCF crack growth rate, the RCF crack will be worn away. ${ }^{9}$ But, having a wear rate less than the crack growth rate results in growth of the crack until it causes failure hence there is a need to find an optimum combination of the two to prevent crack growth and wear. ${ }^{9}$

\subsection{Wheel and Rail Materials}

Pearlitic and bainitic steels are the most common materials for wheel and rail applications due to their remarkable properties and low production costs. Microstructure influences both wear and RCF properties of wheel and rail materials significantly.${ }^{10}$ Several studies have been conducted to try to find out the effect the microstructure has on wear and RCF properties of wheel and rail steels. Currently, most standards require steel with hardness of 250-300 HB for use in wheels applications and 300-400 HB for rail applications as an excess in those values of hardness result in an increase in operating and production costs. ${ }^{11,12}$ Different studies have been conducted to find the effect hardness has on wear performance of rail and wheel steels. Work done by Stock and Pippan ${ }^{13}$ has shown that there is a relationship between hardness and resistance against wear and RCF for pearlitic steel grades on a voestalpine Schienen $\mathrm{GmbH}$ test rig. Increasing the hardness resulted in an increase in both RCF life and wear resistance hence improving the fatigue life of rails..$^{13}$ A study on fracture and fatigue crack growth analysis of rail steels by Aglan 
et al. ${ }^{14}$ has shown that bainitic steels have ultimate strength, yield strength and strain to failure higher than that of pearlitic steels. But recent studies have shown that pearlitic steels have remarkable wear resistance due to their unique microstructure which consists of refined interlamellar spacing made up of cementite and ferrite..$^{15,16}$ Hardness of pearlitic steels is influenced by the lamellae spacing with hardness increasing as spacing becomes finer. ${ }^{15}$ In SA rail operators currently use wheel and rail steels made of medium and high-carbon steels with pearlitic microstructures with wheel steels manufactured from Association of American Railroad (AAR) Classes shown in Table 1.

Table 1: Brinell hardness specifications for different classes of AAR wheel steels and their applications ${ }^{17}$

\begin{tabular}{lll}
\hline Class & $\begin{array}{l}\text { Brinell } \\
\text { Hardness (Rim) }\end{array}$ & Type of Application \\
\hline L & $197-277$ & $\begin{array}{l}\text { High-speed service with more } \\
\text { severe braking conditions than other } \\
\text { classes and light wheel loads. }\end{array}$ \\
\hline A & $255-321$ & $\begin{array}{l}\text { High-speed service with severe } \\
\text { braking conditions, but with } \\
\text { moderate wheel loads }\end{array}$ \\
B & $302-341$ & $\begin{array}{l}\text { High-speed service with severe } \\
\text { braking conditions and heavier } \\
\text { wheel loads }\end{array}$ \\
C & $321-363$ & $\begin{array}{l}\text { Service with light braking } \\
\text { conditions and heavy wheel loads } \\
\text { and service with heavier braking } \\
\text { conditions where off-tread brakes } \\
\text { are employed }\end{array}$ \\
\hline
\end{tabular}

Studies ${ }^{16,18}$ have been conducted to find the effect that pearlite interlamellar spacing has on wear. Clayton and Danks ${ }^{18}$ have shown that pearlitic steels with finer interlamellar spacing have lower wear rates compared to those with larger spacing as shown on Figure 1. Pearlite is made of a lamella structure consisting of alternating layers of ferrite and cementite. The ability of pearlitic rail steels to show remarkable wear resistance is also because pearlitic microstructure can align parallel to the wear surface forming a mosaic of cementite flakes. ${ }^{16}$ Forming a mosaic of cementite flakes makes the exposed area of fraction to increase at the contact area making pearlitic rail steels to be more superior in terms of wear resistance compared to conventional bainitic microstructures which are unable to do so. $\frac{16}{6}$

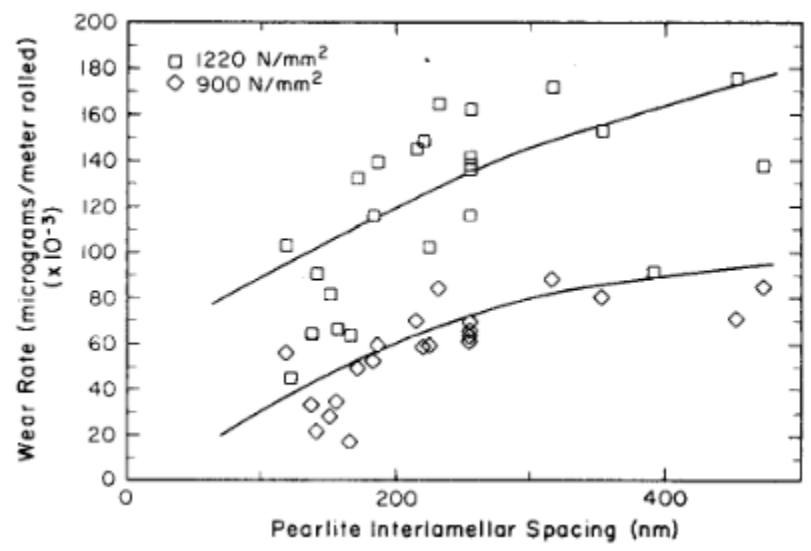

Figure 1: Wear rate against pearlite interlamellar spacing for several rail chemistries and heat treatments at $1220 \mathrm{~N} / \mathrm{mm}^{-2}$ and $900 \mathrm{~N} \mathrm{~mm}^{-2}$ contact pressures ${ }^{18}$

\subsection{Wear Testing and Simulation}

For wear testing and simulation, test rigs are used in railway industries to provide information on the mechanics and dynamics of railway systems in controlled environments and are cheaper alternatives to field testing. ${ }^{19}$ The information obtained from test rigs is used to understand the behaviour of the interaction between the rail and wheel. There are different experimental methods used to study the mechanisms by which wear occurs by simulating the conditions experienced by materials in service which can be in full scale or small-scale. Those experimental methods consist of the following setups: (a) pin-on-disc; (b) block-on-ring; (c) pinon-reciprocating plate; (d) twin disc. ${ }^{20}$ From those simulations, valuable information on wear rates and coefficients of friction can be obtained..$^{20}$ It is very crucial to choose the right testing method for a particular application so that the test is a true representation of the whole system as experienced. For sliding wear testing, the Archard wear model is used to calculate the wear volume. The Archard wear model relates the wear volume to material hardness, load applied and sliding distance. According to Archard's wear model, wear volume can be calculated using equation 1.1 .

$$
V=k \frac{W L}{H}
$$

Where $\mathrm{V}$ is the volume of worn material $\left(\mathrm{m}^{3}\right), \mathrm{k}$ is a dimensionless wear coefficient, $\mathrm{W}$ is the normal load $(\mathrm{N})$, L sliding distance $(\mathrm{m}), \mathrm{H}$ is the hardness of the softer contacting surface $\left(\mathrm{N} / \mathrm{m}^{2}\right)$. According to the Archard wear model, the wear volume increases with an increase in sliding distance and applied load. This model is useful in the railway industry for prediction of wheel/rail wear even though the principal cause of wheel/rail wear is not only pure sliding but a combination with other mechanisms such as rolling wear and RCF. Friction also plays an important role in wear of wheel and rail materials. It is defined using coefficient of friction $(\mu)$ which is the ratio of the frictional force $(F)$ and the normal load $(\mathrm{W})$ both measured in Newtons $(\mathrm{N})$ related using equation 1.2. Friction is not a material property and it is system responsive as it depends on several factors such as lubrication and contact conditions. ${ }^{21}$

$$
\mu=\frac{F}{W}
$$

During wear testing and simulation, at the beginning of the test the coefficient of friction rapidly increases in the non-steady-state region up until it starts to become constant where the material would have reached a steady-state region. In the steady-state region, the coefficient of friction remains constant unless one of the test parameters such as force and lubrication are changed. For this work, AAR class B wheel steels and BS EN 13674-1:2011 rail steels with a 60E1/UIC60 flat bottom rail type profile were used to study their wear performance under dry sliding conditions using RTEC Multi-Function Tribometer. 


\section{Experimental Methods}

\subsection{Characterisation}

The wheel and rail specimen were supplied by Mintek. Their chemical composition analysis (Table 2) was done using spark emission spectrometry and compared to their respective standards. Hardness testing for both wheel and rail materials was conducted using Vickers hardness testing under a load of $10 \mathrm{kgf}$ on a Struers Duramin-40 machine. To observe the as-received microstructures of the wheel and rail samples under optical microscopy (OM) and scanning electron microscopy (SEM), samples were ground and polished to $1 \mu \mathrm{m}$ surface finish and etched with $2 \%$ Nital etchant. SEM was also use to measure the interlamellar spacing of both wheel and rail steels.

\subsection{Sliding Wear Testing}

For sliding wear testing, the wheel and rail specimen were ground and polished to a surface roughness of $3 \mu \mathrm{m}$. Sliding wear testing was done using a RTEC Multi-Function Tribometer (MFT-5000) which uses a ball-on-reciprocating plate concept with E52100 alloy steel of grade 25 testing balls of diameter $6.350 \mathrm{~mm}$. The speed of reciprocating plate was set at $4 \mathrm{~mm} / \mathrm{s}$. The tests were done at different sliding distances between $1200 \mathrm{~mm}$ and $7200 \mathrm{~mm}$ under applied loads of $75 \mathrm{~N}$ and $100 \mathrm{~N}$ for both rail and wheel materials. All tests were done at room temperature under dry sliding conditions. The Tribometer had a force transducer to measure the frictional forces experienced by specimens during testing. From the known values of the applied loads and the frictional forces obtained by the force transducer the values of coefficient of friction were calculated using equation 1.2. After wear testing, the worn specimens were observed under optical microscopy and scanning electron microscopy to observe the morphology of the worn surfaces and size of the wear tracks. Vickers microhardness tests were conducted using a load of 200 gf along the cross-sections of both wheel and rail steels to investigate the depth of plastic deformation and work hardening.

\section{Results and Analysis}

\subsection{Microstructures of the as-received materials}

After conducting the chemical composition (Table 2) and hardness test (Table 3), the wheel specimens were found to conform to class B wheel steels of the AAR M-107/M-208 standard while the rail specimens conformed to BS EN 13674-1:2011 standard with a $60 \mathrm{E} 1 / \mathrm{UIC} 60$ flat bottom rail type profile $(60.21 \mathrm{~kg} / \mathrm{m})$.
Figure 2 and Figure 3 show the Optical microscopy (OM) and Scanning electron microscopy (SEM) micrographs of the rail and wheel materials respectively. As may be seen, both are fully pearlitic and the lamellar spacing of the rail appeared visually to be coarser and the same was confirmed by the lower hardness values of the wheel steel.

\subsection{Coefficient of Friction}

The coefficient of friction (COF) was found to be heavily dependent on load for both wheel and rail steels. When the load was increased from $75 \mathrm{~N}$ to $100 \mathrm{~N}$ the COF decreased for both materials as shown in Figure 4 and, the decrease was much greater for the wheel steel. For rail steel under a load of $75 \mathrm{~N}$, the COF varied between 0.53 and 0.60 while for the wheel material varied between 0.51 and 0.59 . When the applied load was increased to $100 \mathrm{~N}$, the coefficient of friction for rail varied between 0.29 and 0.53 while for wheel varied between 0.21 and 0.24 . Varying the COF with sliding distance/ time under applied load of $75 \mathrm{~N}$ as shown on Figure 5 shows that the COF initially increased rapidly at low sliding distances and thereafter it reached a steady. Literature ${ }^{22,23}$ has demonstrated that high values of COF result in high rates of wear especially under dry conditions whereas low values of frictions result in poor adhesion at the wheel rail contact which may lead to longer braking distance resulting in the train overrunning.

\subsection{Wear Track Width Measurements}

Increasing the sliding distance has also been found to increase the average wear track width on both wheel and rail steels. On rail steels, when the sliding distance was increased from $1200 \mathrm{~mm}$ to $7200 \mathrm{~mm}$ the average wear track width increased from $600 \mu \mathrm{m}$ to $792 \mu \mathrm{m}$ under an applied load of $75 \mathrm{~N}$. The same trend was also observed on wheel steels where the average wear track width increased from $471 \mu \mathrm{m}$ to $760 \mu \mathrm{m}$ under the same conditions. The increase in wear track width with sliding distance was even greater for rail material when the applied load was increased to $100 \mathrm{~N}$. This agrees with the Archard wear model as an increase in sliding distance and load results in an increase in wear volume and according to ASTM G133 - 05(2016) $)^{24}$ the wear volume increases with an increase in wear track width. Rail steels had larger wear track widths as compared to wheel steels under the same conditions. When a load of $100 \mathrm{~N}$ was applied at a sliding distance of $1200 \mathrm{~mm}$, the rail steel had a wear track width of 786 $\mu \mathrm{m}$ while for wheel steel was $418 \mu \mathrm{m}$. The same was observed when the sliding distance was increased to $7200 \mathrm{~mm}$ where the rail material had a wear track width of $948 \mu \mathrm{m}$ while the wheel had a wear track width of $655 \mu \mathrm{m}$ as shown on micrographs from Figure

Table 2: Chemical composition (mass \%) of wheel and rail samples

\begin{tabular}{lcccccccc}
\hline Material & $\mathbf{C}$ & $\mathbf{M n}$ & $\mathbf{P}$ & $\mathbf{S}$ & $\mathbf{S i}$ & $\mathbf{N i}$ & $\mathbf{C r}$ & $\mathbf{M o}$ \\
\hline Rail & 0.79 & 1.17 & 0.013 & 0.016 & 0.388 & 0.061 & 0.197 & 0.0070 \\
Wheel & 0.67 & 0.85 & 0.017 & 0.0072 & 0.356 & 0.096 & 0.17 & 0.033 \\
\hline
\end{tabular}

Table 3: Vickers hardness values and inter-lamellar spacing of wheel and rail steels

\begin{tabular}{ccc}
\hline Material & Average Vickers hardness (HV10) & Average inter-lamellar spacing (nm) \\
\hline Rail & $294 \pm 8$ & $185 \pm 50$ \\
Wheel & $334 \pm 10$ & $110 \pm 27$ \\
\hline
\end{tabular}



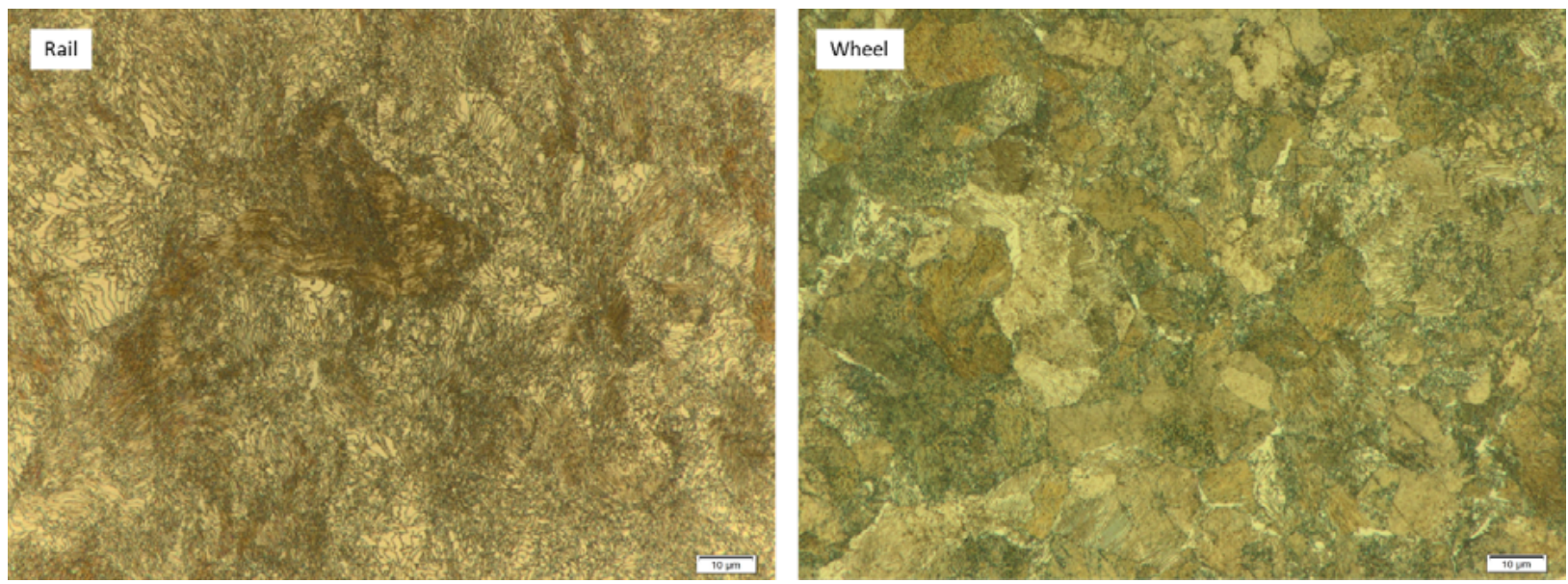

Figure 2: Optical microscopy micrographs of as-received rail and wheel steels showing pearlitic microstructures consisting of alternating layers of ferrite and cementite
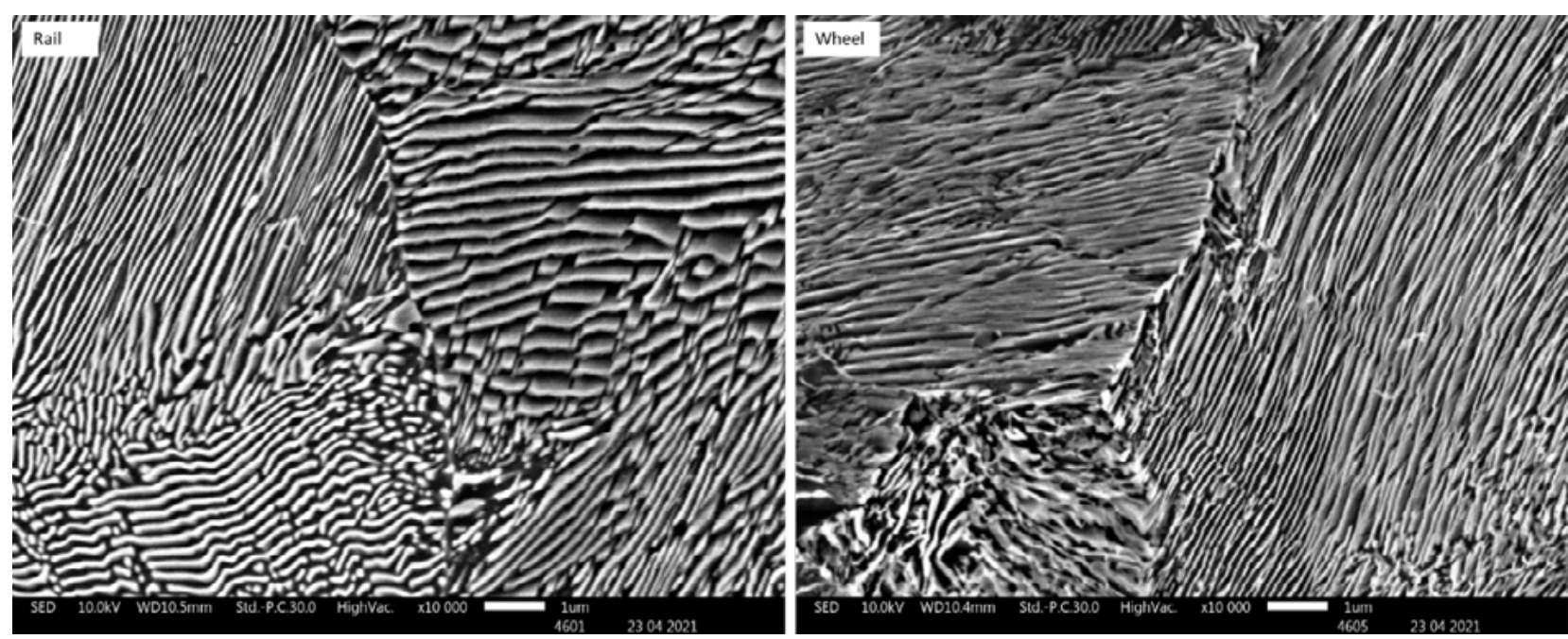

Figure 3: SEM micrographs of as-received rail and wheel steels showing a lamellae structure consisting of alternating layers of ferrite and cementite

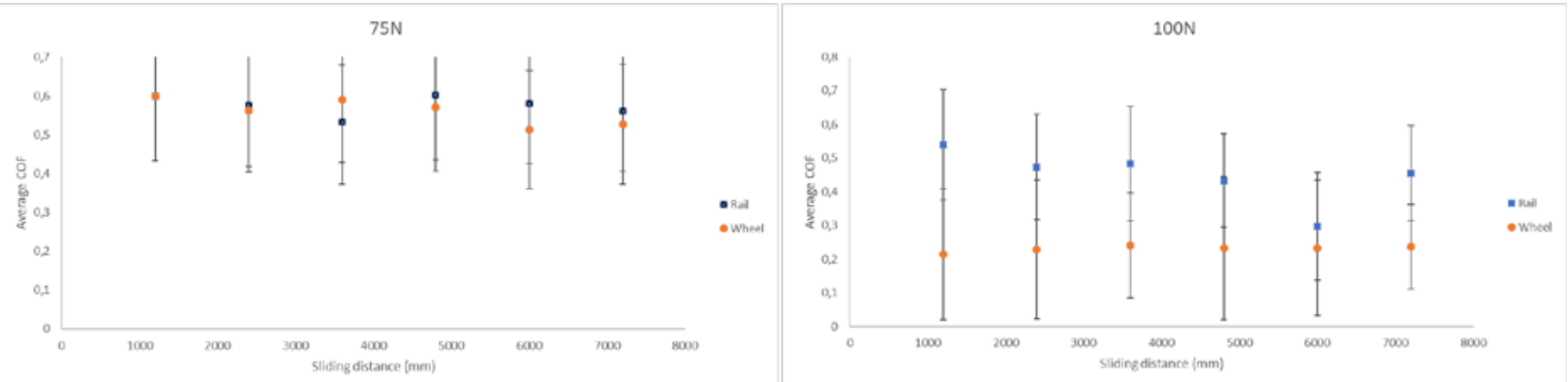

Figure 4: Average coefficient of friction (COF) vs sliding distance for wheel and rail materials under applied loads of $75 \mathrm{~N}$ and $100 \mathrm{~N}$

$75 \mathrm{~N}$
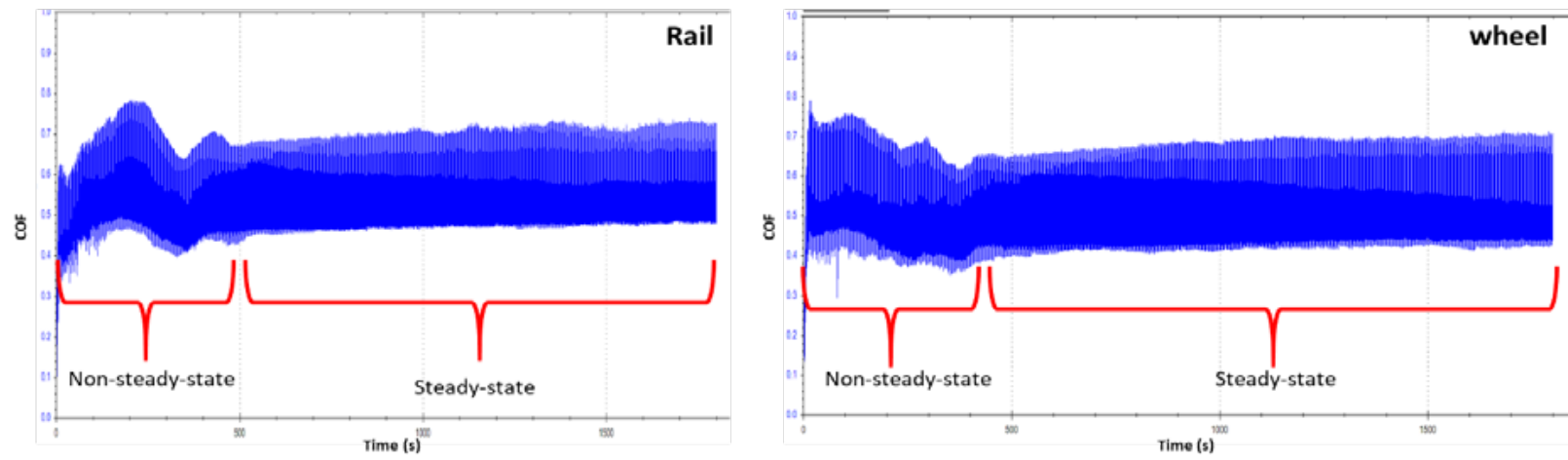

Figure 5: Coefficient of friction (COF) vs. time showing the non-steady-state and steady-state regions at an applied load of $75 \mathrm{~N}$ for both wheel and rail materials 

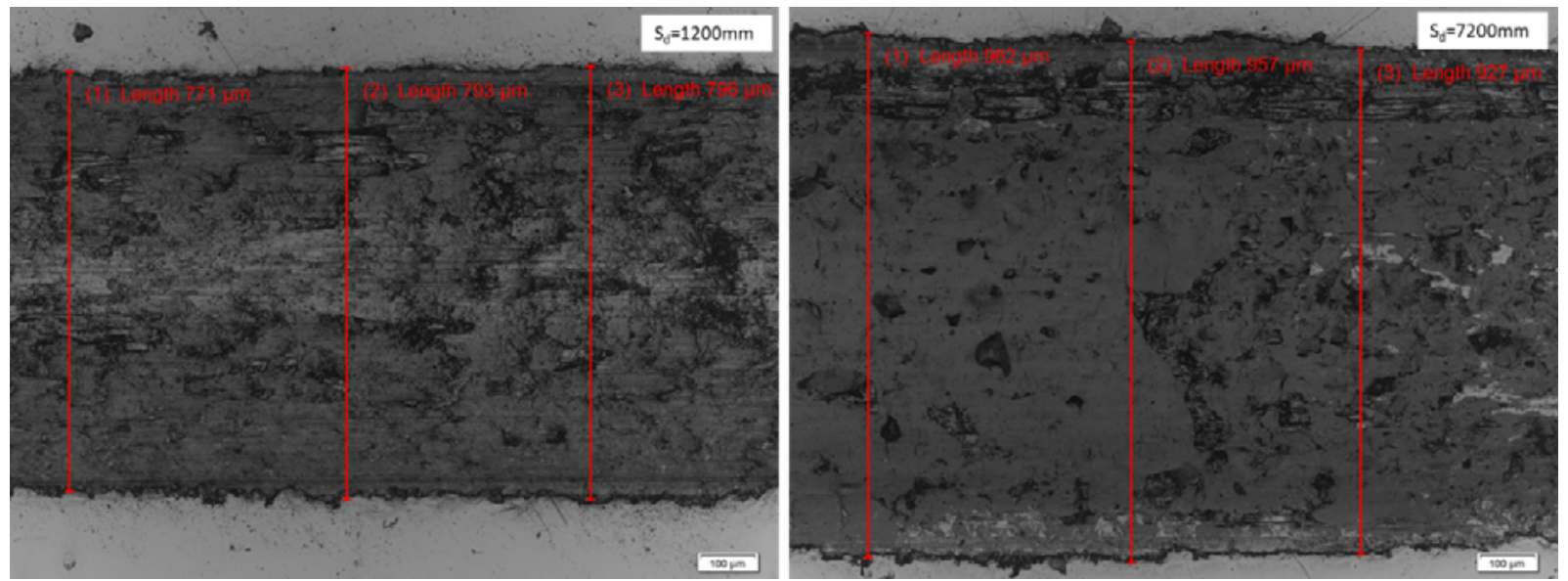

Figure 6: Rail wear track profiles at different sliding distances $\left(\mathrm{S}_{\mathrm{d}}\right)$ of $1200 \mathrm{~mm}$ and $7200 \mathrm{~mm}$ under an applied load of $100 \mathrm{~N}$ showing the wear track width
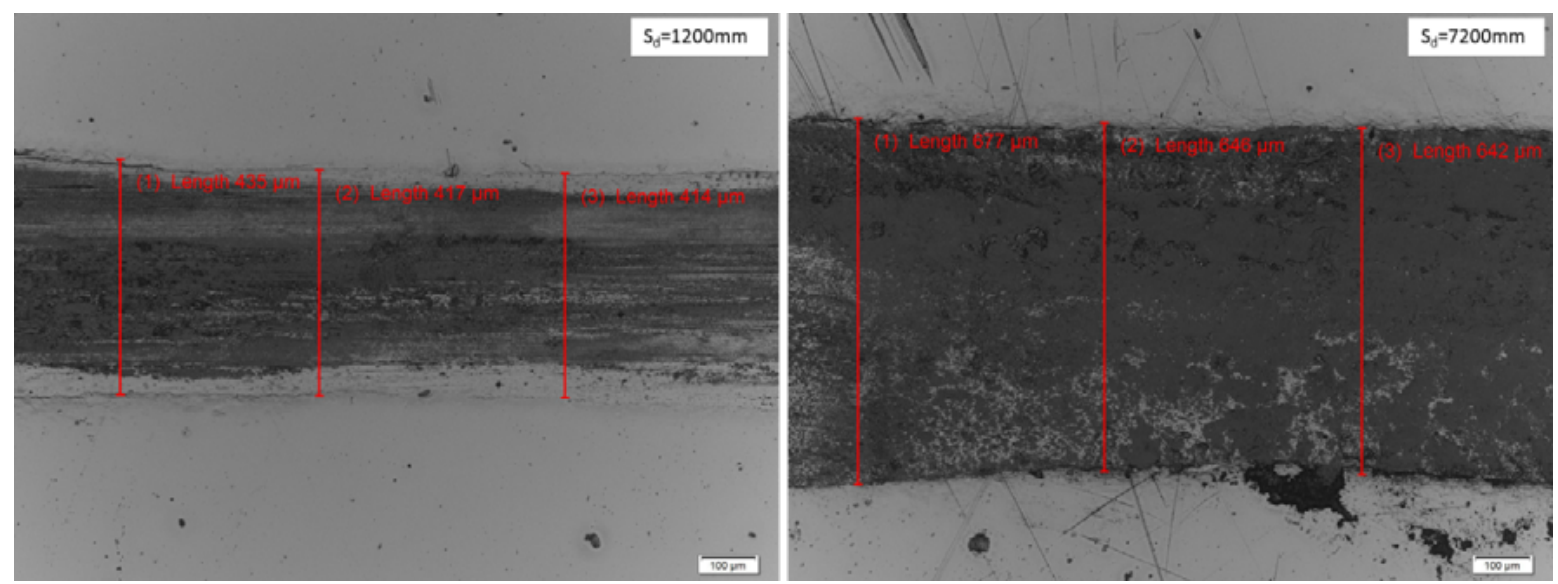

Figure 7: Wheel wear track profiles at different sliding distances $\left(\mathrm{S}_{\mathrm{d}}\right)$ of $1200 \mathrm{~mm}$ and $7200 \mathrm{~mm}$ under an applied load of $100 \mathrm{~N}$ showing the wear track width

6 and Figure 7. The reason for this is because wheels steels are more resistant to wear than rail steels as they are harder than rail steels with finer interlamellar. The as-received hardness of rail and wheel steels were $294 \pm 8$ HV10 and $334 \pm 10$ HV10 respectively with an average interlamellar spacing of $185 \pm 50 \mathrm{~nm}$ and $110 \pm$ $27 \mathrm{~nm}$ respectively shown on Table 3 . The effect of interlamellar spacing on wear resistance agrees with the work done Clayton and Danks ${ }^{18}$ who have shown that pearlitic steels with finer interlamellar spacing have lower wear rates compared to those with larger spacing. On the effect of hardness, the results agree with the work done by Stock and Pippan ${ }^{13}$ who have shown that pearlitic steels with higher hardness are more resistant to wear than those with lower hardness.

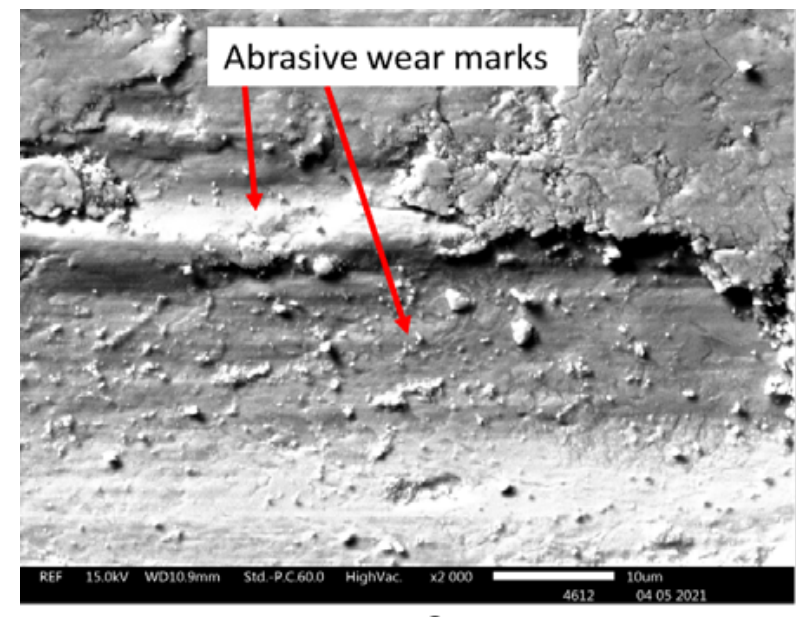

a

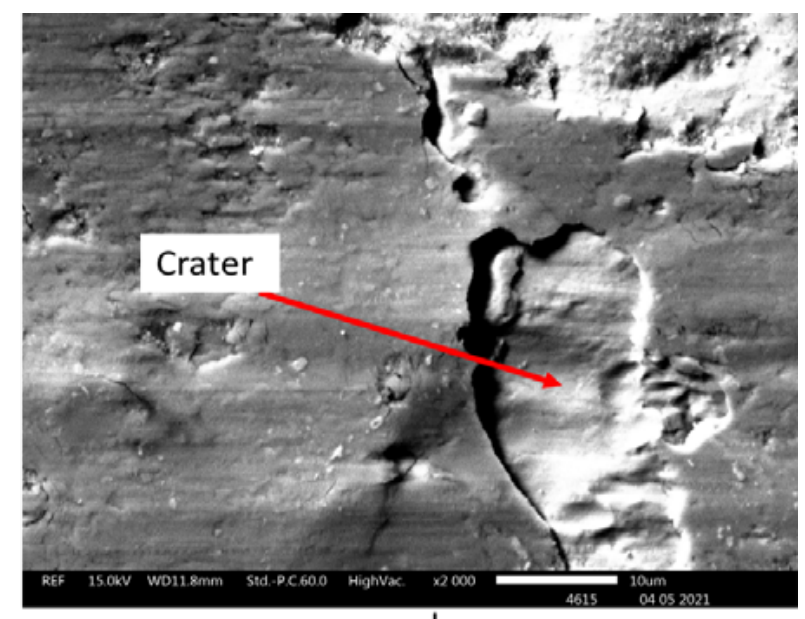

b

Figure 8: SEM micrographs of the rail specimen showing wear track morphology at different sliding distances of (a) $1200 \mathrm{~mm}$ and (b) $7200 \mathrm{~mm}$ under an applied load of $75 \mathrm{~N}$ 


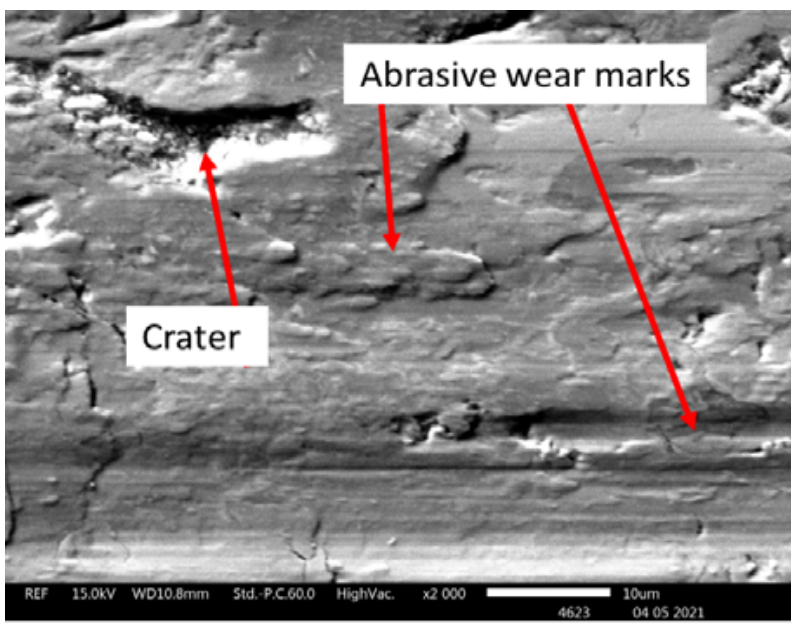

a

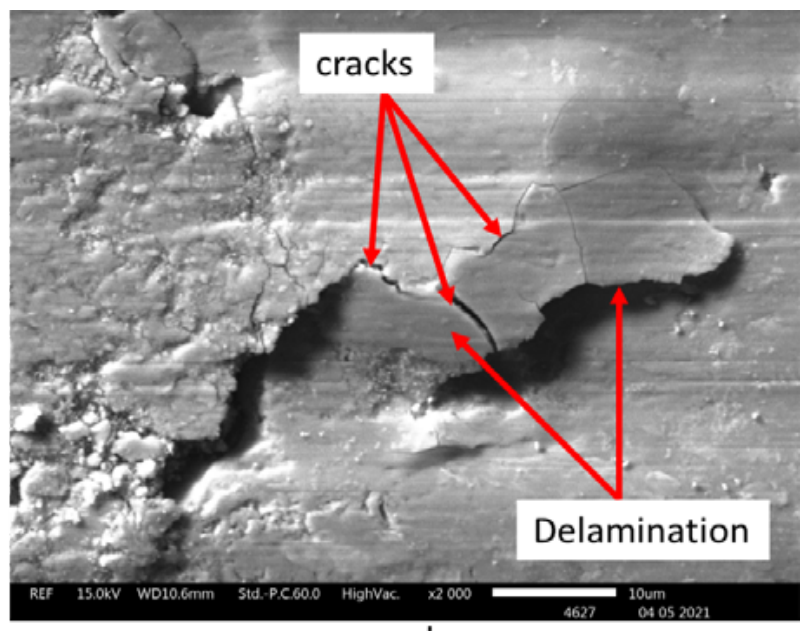

b

Figure 9: SEM micrographs of the wheel specimen showing wear track morphology at different sliding distances of (a)1200 mm and (b) $7200 \mathrm{~mm}$ under an applied load of $75 \mathrm{~N}$

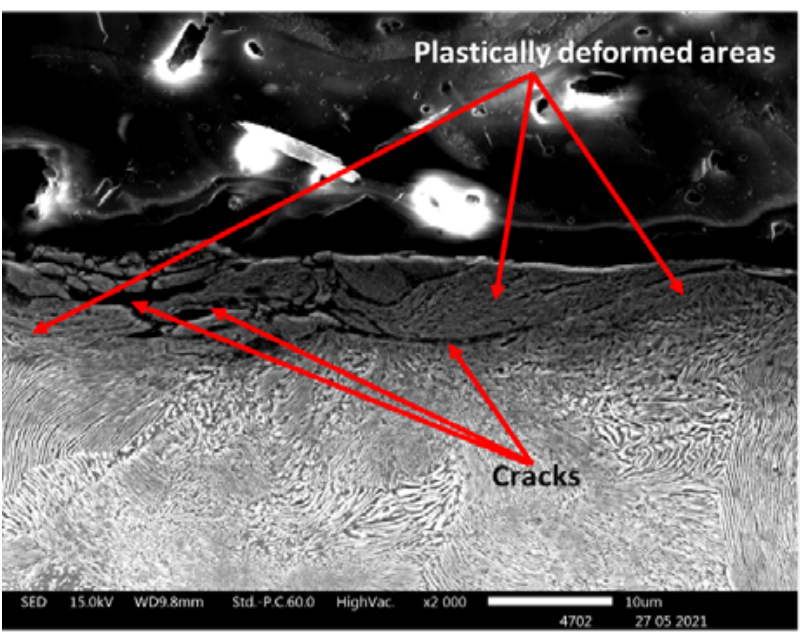

a

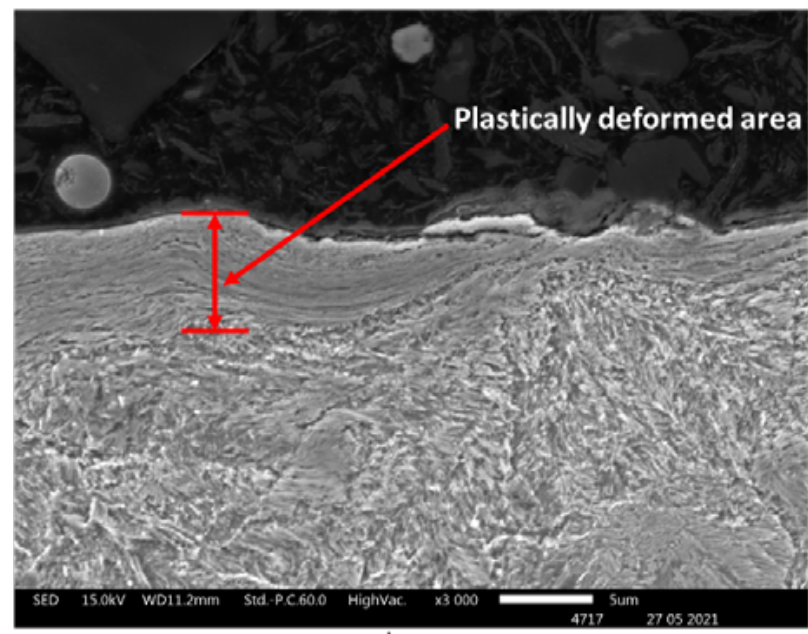

Figure 10: Plastic deformation of (a) rail showing the cracks in the transverse plane of the specimen and (b) wheel specimen showing the depth of plastic deformation both under a load of $75 \mathrm{~N}$ and sliding distance of $1200 \mathrm{~mm}$

\subsection{Wear Track Morphology}

From the SEM micrographs on Figure 8 and Figure 9 it is evident that increasing the sliding distance from $1200 \mathrm{~mm}$ to $7200 \mathrm{~mm}$ leads to severe damage on both materials. There is evidence of delamination and crack formation (Figure 9) on the wheel sample when the sliding distance was increased from $1200 \mathrm{~mm}$ to $7200 \mathrm{~mm}$ causing severe wear. From the energy dissipation model studied by Lewis and Dwyer-Joyce ${ }^{25}$ severe wear is mainly dominated by surface cracking and mass loss due to delamination which were observed on the wheel sample. At lower sliding distance of 1200 $\mathrm{mm}$ for both materials, there is evidence of abrasive wear shown by abrasive wear marks on worn surfaces which is an indication of mild wear. For the rail material, when the sliding distance was increased to $7200 \mathrm{~mm}$ craters (Figure 8b) started to form due to excessive sliding distance causing loss of material by spalling.

\subsection{Plastic Deformation and Microhardness Profiles}

Figure 10 shows SEM micrographs of the cross-section of the wear track that formed as a results of sliding wear test. As seen, there is evidence of plastic deformation occurring on both wheel and rail specimens and some cracks occurring due application of repeated loading during sliding. The Vickers microhardness tests results confirmed that plastic deformation has occurred as there was an increase in the surface hardness on both materials as shown on

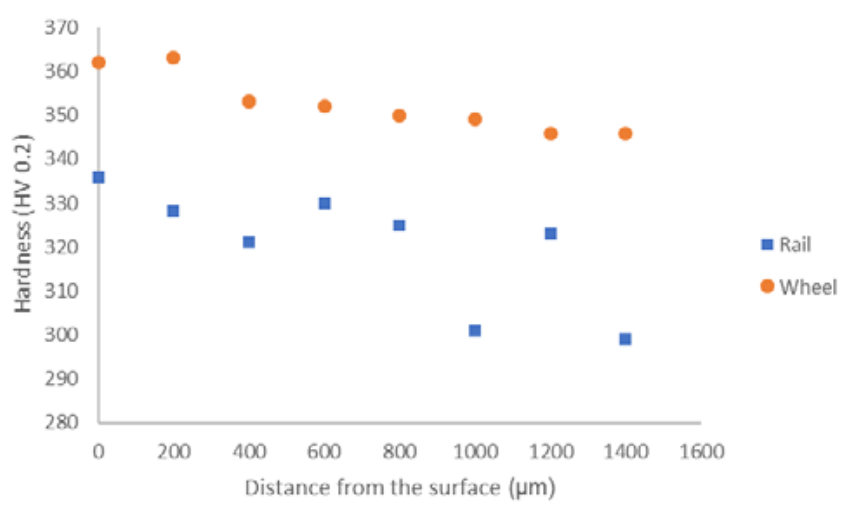

Figure 11: Wheel and rail steels hardness profiles after wear testing under an applied load of $75 \mathrm{~N}$ and sliding distance of 7200 $\mathrm{mm}$ showing the depth of plastic deformation 
hardness profiles on Figure 11. The wheel steel had a surface micro hardness of 362 HV0.2 compared to the rail's 336 HV0.2 after wear testing. The wheel surface hardness increased from $334 \mathrm{HV}$ to $362 \mathrm{HV}$ after test while rail surface hardness increased from 294 $\mathrm{HV}$ to $336 \mathrm{HV}$. This confirms that indeed some plastic deformation has occurred which resulted in work hardening.

\section{Conclusions}

The wheel material was more resistant to sliding wear as compared to rail material at both applied loads of $75 \mathrm{~N}$ and $100 \mathrm{~N}$. Increasing the load was found to reduce the COF for both wheel and rail materials. The opposite was observed for wear track width as increasing the load resulted in an increase in wear track width. Sliding distance was found to influence both COF and wear track width. Increasing the sliding distance increased both coefficient of friction and wear track width. The COF increased up until a point where a steady-state was reached where it became constant. The rail was found to have higher wear rates due to larger wear track width and higher values of COF. It has been found in both wheel and rail materials that increasing the sliding distance has been found to causes severe wear. This was evident from SEM micrographs which showed some crack formation and craters causing loss of material by delamination and spalling. Plastic deformation has been confirmed on both materials with a significant increase in surface hardness at the contact area of the wear track cross-section.

The test rig was successful in proving sliding wear and parameters such as load and sliding distance were easily varied to see their effects on sliding wear (wear track width) and COF. However, the rig was unsuccessful in proving the other two major damage mechanisms being rolling wear and $\mathrm{RCF}$ which are also experienced by the wheel and rail during movement of train on rail tracks. Also, it had limitations on the amount of load that can be applied during testing.

\section{Future Work}

In future, more work should be done using a rig that that will be able to simulate both rolling, sliding and RCF. To simulate all the three major wear mechanisms, a test rig which uses the twin disc concept must be used and the ball-on-reciprocating plate should only be used for preliminary testing.

\section{Acknowledgement}

The authors would like to thank the following organisations for making this project possible: Mintek for financial support and supplying materials, University of Pretoria for technical support and Botswana International University of Science and Technology (BIUST) for use of their rig for wear testing.

\section{References}

1. R. Lewis and U. Olofsson, "Basic tribology of the wheel-rail contact," in Wheel-Rail Interface Handbook, Cambridge, Woodhead, 2009, pp. 34-57.

2. A. Kapoor, I. Salehi and A. M. S. Asih, "Rolling Contact Fatigue (RCF)," in Encyclopedia of Tribology, Boston, Springer, 2013, pp. 2736-2969.
3. V. Manoj, K. M. Shenoy and K. Gopinath, "Developmental studies on rolling contact fatigue test rig," Wear, vol. 264 , no. $7-8$, p. $708-718$, 2008 .

4. D. Nelias, M. L. Dumont, F. Champiot, A. Vincent, D. Girodin, R Fougeres and L. Flamand, "Role of Inclusions, Surface Roughness and Operating Conditions on Rolling Contact Fatigue," Journal of Tribology, vol. 121, no. 2, pp. 240-251, 1999.

5. E. . E. Magel, "Rolling Contact Fatigue: A Comprehensive Review," U.S. Department of Transportation, Federal Railroad Administration, Washington, 2011.

6. S. Maropoulos and N. Ridley, "Inclusions and fracture characteristics of HSLA steel forgings," Materials Science \& Engineering A, vol. 384, pp. 64-69, 2004.

7. M. Takikawa and Y. Iriya, "Laboratory simulations with twin-disc machine on head check," Wear, vol. 265, no. 9-10, p. 1300-1308, 2008.

8. R. A. Smith, "The wheel-rail interface-some recent accidents," Fatigue \& Fracture of Engineering Materials \& Structures, vol. 26 no. 10, pp. 901-907, 2003.

9. J.-W. Seo, H.-K. Jun, S.-J. Kwon and D.-H. Lee, "Rolling contact fatigue and wear of two different rail steels underrolling-sliding contact," International Journal of Fatigue, vol. 83, no. 2, p. 184-194, 2016.

10. X. J. Zhao, J. Guo, H. Y. Wang, Z. F. Wen, Q. Y. Liu, G. T. Zhao and W. J. Wang, "Effects of decarburization on the wear resistance and damage mechanisms of rail steels subject to contact fatigue," Wear, Vols. 364-365, pp. 130-143, 2016.

11. D. Markov , "Laboratory tests for wear of rail and wheel steels," Wear, 181-183(PART 2), pp. 678-686, 1995.

12. R. Ordóñez Olivares, C. I. Garcia and F. C. Robles Henrández, "Metallurgy of high-carbon steels for railroad applications," Journal of the Southern African Institute of Mining and Metallurgy, vol. 113, no. 2, pp. 155-162, 2013.

13. R. Stock and R. Pippan, "RCF and wear in theory and practice-The influence of rail grade on wear and RCF," Wear, vol. 271, no. 1-2, pp. 125-133, 2011.

14. H. A. Aglan and M. Fateh, "Fracture and Fatigue Crack Growth Analysis of Rail Steels," Journal of Mechanics of Materials and Structures, vol. 2, no. 2, pp. 335-346, 2007.

15. J. Tunna, J. Sinclair and J. Perez, "A review of wheel wear and rolling contact fatigue," Proceedings of the Institution of Mechanical Engineers, Part F: Journal of Rail and Rapid Transit, vol. 221, no. 2, p. 271-289, 2007.

16. A. J. Perez-Unzueta and J. H. Beynon, "Microstructure and wear resistance of pearlitic rail steels," Wear, vol. 162-164, no. Part A, pp. 173-182, 1993.

17. Association of American Railroads (AAR) , "AAR M-107/M-208 Standard: AAR Manual of Standards and Recommended Practices: Wheels and Axles Wheels," Association of American Railroads , Washington, D.C, 2016.

18. P. Clayton and D. Danks, "Effect of interlamellar spacing on the wear resistance of eutectoid steels under rolling-sliding conditions," Wear vol. 135 , no. 2 , pp. 369-389, 1990.

19. S. . Z. Meymand, J. M. Craft and M. Ahmadian, "On the Application of Roller Rigs for Studying Rail Vehicle Systems," in Proceedings of the ASME 2013 Rail Transportation Division Fall Technical Conference. ASME 2013 Rail Transportation Division Fall Technical Conference, Altoona, 2013.

20. I. Hutchings and P. Shipway, "5 - Sliding wear," in Tribology (Second edition), Oxford, Butterworth-Heinemann, 2017, pp. 107-164.

21. B. Bhushan, Principles and Applications of Tribology, Second Edition, New York: John Wiley \& Sons, Ltd, 2013.

22. W. J. Wang, H. Wang, H. Y. Wang, J. Guo, Q. Y. Liu, M. H. Zhu and X. S. Jin, "Sub-scale simulation and measurement of railroad wheel/ rail adhesion under dry and wet conditions," Wear, vol. 302, no. 1-2, p. 1461-1467, 2013

23. C. Hardwick, R. Lewis and D. T. Eadie, "Wheel and rail wearUnderstanding the effects of water and grease," Wear, vol. 314, no. 1-2, pp. 198-204, 2014.

24. ASTM International, "ASTM G133 - 05, Standard Test Method for Linearly Reciprocating Ball-on-Flat Sliding," ASTM International, West Conshohocken, PA, 2016.

25. R. Lewis and R. S. Dwyer-Joyce, "Wear mechanisms and transitions in railway wheel steels," Proceedings of the Institution of Mechanical Engineers, Part J: Journal of Engineering Tribology, vol. 218, no. 6, p. $467-478,2004$ 